This document is the Accepted Manuscript version of the following article: Hulya Dagdeviren, Matthew Donoghue, and Markus Promberger, 'Resilience, Hardship and Social Conditions', Journal of Social Policy, Vol. 45 (1), pp. 1-20, first published online 21 July 2015.

The final, published version is available online at DOI: https://doi.org/10.1017/S004727941500032X

(C) 2015 Cambridge University Press. 


\title{
RESILIENCE, HARDSHIP AND SOCIAL CONDITIONS ${ }^{1,2}$
}

\author{
Hulya Dagdeviren*, Matthew Donoghue** and Markus Promberger***1
}

\begin{abstract}
:
This paper provides a critical assessment of the highly agent-centric conceptualisation of the term 'resilience'- and its hightly agent-centric conceptualisation - when applied to how individuals and households respond to hardship. We provide an argument for social conditions to be embedded into the framework of resilience analysis. Drawing on two different perspectives in social theory, namely structure-agent nexus and path dependency, we aim to demonstrate that the concept of resilience, if understood in isolation from the social conditions within which it may or may not arise, can result in a number of problems. This includes misidentification of resilience, ideological exploitation of the term and inability to explain intermittence in resilience.
\end{abstract}

\section{Introduction}

The growing literature on resilience contains some well-versed reviews on the use of this concept in different subject areas, particularly in engineering, ecology and psychology. The unit of analysis across the disciplines varies but the overarching theme in all is how the subject of analysis responds to an unexpected shock, pressure, adversity or disturbance.

The transfer of this concept to social sciences in general and social policy in particular is relatively new. Despite this, academic work on the subject has been prolific. Two different academic journals on Resilience are now being published, one focusing on environmental humanities and the other on its relevance to political studies. There are departments, centres and groups of social science researchers working on various dimensions of resilience. In addition, the term has now entered into the lexicon of governments, as well as the terminology of NGOs. For example, the Cabinet Office in the UK now produces annual Sector Resilience Plans, other organisations such as the Joseph Rowntree Foundation, the New Economics Foundation (NEF, 2010), the Social Market Foundation (SMF, 2014), and the Trades Union Congress (TUC, 2012: 1) all refer to resilience especially to discuss the social effects of the 2008 financial crisis and the response to it at various levels. The Rockefeller Foundation in the United States has launched the ' 100 Resilient Cities' initiative, which is aimed at 'helping cities around the world become more resilient to the physical, social, and economic challenges that are a growing part of the $21^{\text {st }}$ Century' (Rockerfeller Foundation, 2015). The World Bank (2013), International Monetary Fund (2013) and the OECD (2014) have all began to develop a focus on various forms of resilience.

The widespread use of the concept of 'resilience' in social contexts has been associated with a number of developments. The first is related to the terror attacks, hazards associated with climate change (e.g., floods) and social disorders. ${ }^{3}$ The second is related to the global impacts of the 2008 financial crisis which have led social science researchers to refer to resilience as an analytical tool addressing the responses of individuals, households, communities and regions in the face of adversity (Raco and Street, 2012; Myant and Drahokoupil, 2012; Lowndes and McCaughie, 2013; Martin and Sunley, 2014).

$\left({ }^{*}\right)\left({ }^{* *}\right)$ University of Hertfordshire, Business School, College Lane, Hatfield AL10 9AB, emails: h.dagdeviren@herts.ac.uk; m.donoghue@herts.ac.uk

$(* * *)$ Institute for Employment Research of the Federal Employment Agency, Regensburger Str. 104 D-90478 Nürnberg, Germany, email: markus.promberger@iab.de 
The overarching objective of this paper is related to the second point above. We aim to discuss the potential merits and limitations of the concept of resilience in understanding human behaviour under economic hardship, a recurring theme in social policy following the 2008 crisis. This is important given the considerable lack of conceptual clarity about what 'the social' in resilience might be, and how society, social structures and historical influences feature in the formation of resilience at both theoretical and empirical levels. More specifically, we argue that the discourse of resilience must be viewed within the context of the social conditions in which it arises. In particular, we discuss the drawbacks of not considering the influence of structural conditions and path dependency on the resilience of social subjects.

\section{The application of the concept of 'resilience' to households / individuals in the context of economic hardship}

The concept of resilience has a number of attractions. For example, rather than designating those who are facing hardship as passive victims, 'resilience' can instead recognise them as resourceful and view them with enhanced agency (e.g., Hoggett, 2001; Frost and Hoggett, 2008: 442; Mitchell, 2013: 7; Tomlinson et al., 2008: 598). In this way, 'resilience' begins a conceptual break with more established concepts regarding poverty and hardship that are perhaps more likely to present those facing hardship as passive victims who are unable to help themselves (e.g., Royce, 2009: 64; Lister, 2002).

Notwithstanding the appeal of the term to this group of progressive scholars, the versatility of the term resilience has been questioned by many. Central to the potential analytical power of the term 'resilience' is how it is defined and what it represents. Although it is commonly understood as a response to a negative shock, ${ }^{4}$ three questions about it have been raised in the literature. The first question is whether responses to ordinary change should be treated as resilience or if resilience is a more relevant term in the context of shocks and serious adversities. For example, Canvin et al., (2009: 40) and Masten (2001: 227) highlight the importance of defining and employing resilience in everyday terms, indicating that otherwise resilience would require extraordinary achievements. Martin and Sunley (2014), on the other hand, argue that the term should be dedicated to the study of shocks.

The second question is related to the state of achievement as a result of being 'resilient'. More specifically, as raised by Martin and Sunley (2014), is resilience the ability of:

a) going back to the initial state after some shock, or

b) absorbing the disturbance and remaining in the same state, or

c) successfully adapting to the adversity and achieving a different state, or

d) turning shocks into opportunity and transforming oneself to a better state?

Of these, the notion of going back to or remaining in the initial state ( $a$ and $b$ ) could be more appropriate for physical or mechanical entities but less so for humans if one considers Dewey's (1896) work implying that perception, reaction, learning and memory will give rise to a new state in the post-shock phase. Hence, increasingly, scholars regard this notion as a complex phenomenon that should be understood as a process, involving any or a multitude of these possibilities. For example, Raco and Street (2012: 1067) regard it as a process in which disturbances provide an opportunity to transform, develop and do new things while Folke et al., (2002) describe the term as the capacity to self-organise, learn and adapt.

Finally, it is argued that potential ambiguities in relation to its meaning and its susceptibility to value judgements make it difficult to use resilience as an objective tool of analysis. This is largely because outcomes associated with it may be valued in different ways in different cultural, ethnic, and socioeconomic settings (Mohaupt, 2009). Nevertheless, social sciences are full of such concepts (e.g., 
'governance', 'class', 'violence'). On the one hand the concepts can imply value judgements. On the other, they are indispensable scientific concepts and tools of analysis.

Probing the meaning and conceptualisation of resilience is important. In this paper, however, we focus on what we term as 'social conditions of resilience' in the context of economic hardship and potential problems of neglecting this dimension.

As stated earlier, the discourse on 'resilience' of households and families in times of economic hardship has partly emerged as an alternative to approaches that presented the disadvantages of the poor as if they had no control over their circumstances. This, according to Canvin et al., (2009), created an expectation of failure. As a reaction to the 'deficit model', which focuses on negative outcomes, narratives on resilience have been used to reflect more positive accounts of the lives of individuals or groups in times of adversity when they turn crises into opportunities (Harrow, 2009; Mohaupt, 2009), create positive changes from setbacks and survive multiple pressures (Batty and Cole, 2010).

Studies in the literature explain resilience in two dimensions.

The first dimension is related to the attributes and character of the units of analysis that make them resilient. These are usually broadly described rather than being specified in detail, often referred to as the ability and skills possessed and attitudes deployed in the face of adversity. Regarding the financial crisis and the ensuing recession, this would be the ability, skill and attitude of households to deal with financial shortfalls, increased cost of living, higher debt, and so on, within a particular system. For example, Batty and Cole (2010: 23) mention maintaining a positive attitude while looking for a job as a form of resilience. Harrison (2013) highlight 'the positive response' from individuals when in economic hardship. Okech et al., (2012: 431) identify resilience in those '...who possess strengths that assist them in recovering from negative experiences; benefit from and contribute to a network of relationships in their communities; seek to restore order and balance to their lives during crises'. Other studies explained resilience as the ability to overcome setbacks and risks of financial and social exclusion (Milne and Rankine, 2013: 7); to cope with poverty and economic instability (De la Rocha, 2006), to accomplish specific goals despite living in poverty (Mullin and Arce 2008), to adapt to risks (Orthner et al., 2004); to develop strategies to meet basic needs (Snel and Staring, 2001); to maintain enriching social networks (CSJ, 2013) and to actively struggle against adversity and achieve some 'ordinary magic' (Canvin et al., 2009).

A number of capacities are seen as central for the resilience of individuals and households. For example, Keck and Sakdapolrak (2013) argue that resilience involves the capacity to a) cope with, b) adapt to and c) transform risks, threats and hardship through absorptive, reactive, preventative and proactive measures. Exceptionally, these authors recognise the role of knowledge and learning for developing a capacity of resilience although various facets of this relationship are not explored fully in their discussion. A number of traits are considered to be helpful. Drawing on the earlier longitudinal studies, especially by Emmy Werner, Seccombe (2002) concludes that various protective factors at individual, family and community level contribute to resilience over the course of a life. At an individual level, being sociable, having a positive view of self, intelligence, good communication and problem-solving skills, good humour, physical and mental health are seen as important. The protection that families offer to individual members through care, affection and emotional support plays a key role. Providing activities within the community also helps individuals to acquire essential social skills and bond with other individuals.

The second dimension of resilience is related to the practices and/or strategies households use in dealing with economic hardship. These centre on making the most of one's own or external resources (Mingione, 1987; Rakodi, 1999) through various routes such as economising or reducing 
consumption, taking on additional work, production for own consumption or participating in an informal exchange economy. It could also involve obtaining support from social networks, state institutions and third sector organisations such as churches and charities. Hossain et al. (2011), for example, in a case study of three towns in the UK found that job losses, income uncertainty for businesses and job insecurity amongst working populations had risen after the crisis. In response to changing circumstances, households used various strategies, including economising on food and fuel, spending less on social life and entertainment and devoting more time to managing tighter budgets.

\section{Social conditions of resilience}

Resilience at an individual level is inherently tied up within wider structural frames and historical developments, rather than being a unique behavioural attribute of individuals or households. Currently, any recognition of these influences has often been pushed to the background or presented with a degree of superficiality. This is implied by Chandler (2013: 278); (see also Duffield, 2012).

Resilience discourse no longer articulates risks or threats as external to the practices or choices of subjects or the society but treats them as products of societies 'internal functioning'. However, the social at the centre of the discourse is devoid of power relations and reduced to the appearances of choices and practices of individuals.

In what follows we argue that social structure and history matter in that the former reflects the environment within which individuals can or cannot be resilient while path dependence can explain the historical process, including the development of structure and the initial conditions that give rise to the resilience of individuals.

\section{Structure agency nexus and resilience}

The application of the concept of resilience in some subject areas such as ecology is considered to be neglecting the role of human agency (Martin and Sunley, 2014). In contrast to this, the debates in social sciences may ignore the role of structural conditions in the resilience of social subjects and may present them as autonomous and therefore unaffected by such influences. Narratives of resilience as a unique individual response to hardship may accentuate personal characteristics and disregard the social conditions in which they emerge.

Hence, the long-standing debate on the structure-agency nexus (Dolfsma and Verburg, 2008) is highly relevant to any discussion on resilience. Let us recapture this debate briefly. In a nutshell, while most schools of thought recognised the interaction between structure and agency, some stressed the prominence of one in forming the other. This is true of the classical Marxist theory in spite of the criticism levied against it for having a highly deterministic view of social entities.

'Man makes his own history, but ... he does not make it out of conditions chosen by himself...' (Marx, 1907: 5)

In other words, while Marx recognised the role of individuals in bringing about radical change, the latter cannot be entirely separated from the developments of the past. ${ }^{5}$ Parsons has been considered a structural determinist but the importance he attributed to voluntary action, individual achievement and personal qualities, especially in his earlier works, show the role he attributed to agency in social systems (1937). The disparate approaches pursued by Durkheim $(1893,1895)$ and Weber (1922) in analysing the role of structure and agency can be viewed in the same way. 
Giddens has been credited for stressing the existence of a 'false-dichotomy' in the structure-agency debate. Instead, he argued for a continuous interaction between the two. (Giddens 1979, see also Sewell 1992). Structure as social roles, rules and resources is considered to be produced and reproduced in what people do, which in turn is constrained and enabled by structure through the use of power, application of sanctions and communication of meaning (1984). However, Giddens implicitly discredited his early writings in his more recent work in which agent-centric explanations explicitly supersede structure. ${ }^{6}$ Another landmark contribution to the debate is in Bourdieu's work on practices, habitus, class-status and distinction $(1977,1984)$. Not only did he recognise the temporality of structures and the capacity of agents to be autonomous but he also viewed agency to be conditioned by social rules, cultural values and conventions. Hence, the limits on agents' autonomy are recognised in their tendency to reproduce existing structures.

Overall, it is well established in the literature that social structure (including norms and traditions, class, gender, ethnic divisions, power relations, colonial influence and their economic and political manifestations) shapes individual behaviour and social relations. On the other hand, although humans are not dupes and have the capacity to show autonomy, their influence on structure is likely to be gradual, involving discontent, isolation and struggle(s) with progression through setbacks.

Let us consider all this in relation to the topic of this paper, that is, resilience of individuals, families or households in times of economic crises. However, before doing so, it may be necessary to attribute some practical meaning to the term. Economic hardship during crisis periods takes the form of income or consumption losses through, say, unemployment, business failures and cuts in public spending. Assume for a moment that resilience in such circumstances is reflected in stemming or recovering losses relatively quickly by finding new lines of income-generating activities or developing strategies to manage and meet the necessary expenses rather than enduring the crisisinduced hardship on a long-term basis.

Going back then, in a given structure if some individuals or families remain resilient despite being subject to economic shock, while others are not, what are the conditions that give rise to their resilience? Is resilience a unique individual trait or is it socially produced, constructed and conditioned? The current perspectives on household resilience place a heavy emphasis on agency with very little recognition of structural conditions of resilience. As discussed in the previous section, resilience is often considered to reflect traits such as attitude and the abilities of individuals to deal with hardship. For example, resilience during and in the aftermath of the 2008 economic crisis is frequently discussed in connection with the depth and breadth of the 'shock', impacts of rising unemployment and declining incomes and how individuals or households respond in the face of changing living conditions. This obscures wider structural factors such as class, asset ownership, redistributive systems, cultural practices and so on. While resilience in times of economic hardship may be an occasional need for high-income households, it is likely to be more relevant for low income and poorer households as argued by Orthner et al. (2004) and Okech et al. (2012) who view households' vulnerability to shocks as associated with their wealth and income.

Likewise, considering resilience in isolation from power, politics and participation may be a futile exercise. This is acknowledged by various studies including Davidson (2010), Mackinnon and Derickson (2012) and Keck and Sakdapolrak (2013). Davidson discusses how concentration of power and privilege influences control over resources and decision making. This in turn determines the outcomes with respect to resilience or a lack of it, both at systemic as well as individual levels. Lack of focus on social conditions of resilience lead Mackinnon and Derickson to conclude that mainstream analyses in resilience studies are conservative in that they fail to incorporate the 'critical role of the state' and neglect inequalities.

By generating a discourse of equivalence between groups and individuals, they often have the effect of suppressing social difference (according to 
class, gender, race, etc.) and masking inequality and hierarchy (MacKinnon

and Derickson 2012: 259).

Indeed, the degree to which households show resilience in times of 'economic shock' depends on the political choices made by the state regarding the operations and reign of the markets. For example, promoting labour market flexibility, including the ease with which employees could be hired and fired, has been a policy choice by many countries globally. Increasing feelings of subjective insecurity are important to understand because, in a recession, more people are relying on this kind of labour to survive (Harrison, 2013: 105-106). In relation to this:

[c]omparative studies on labour market flexibilisation have corroborated that atypical forms of employment such as temporary and part-time employment increase job insecurity (Mau et al. 2012: 659).

Similarly, the presence or absence of systems that afford extensive protection to individuals, through redistribution of wealth and/or protection of income in times of economic adversity, is highly relevant to resilience. This is supported by Hossain et al. (2011) who examined the changes in the living conditions of people in County Tyrone, Newhaven and Oldham in the UK and found that the potential negative effects of the deep recession of recent years had been counteracted somewhat by the welfare system which protected the people in these areas.

Overall, then, a more protective labour market or welfare system may institute a system of socialised resilience while more liberal varieties can expose the working classes as a whole to the risks of severe downturns and leave them to deal with hardship individually.

Amongst the many structural factors, one may also consider rural-urban differences. Resilience is likely to have a different character in rural as opposed to urban areas as rural residents may have reduced access to jobs, community organisations, social networks and so on for a number of reasons, thus leaving them socially excluded. Lack of infrastructure may compound what is potentially a poor employment situation (Philip and Shucksmith, 2003). Room (1995) summarises the issue of rural resilience and poverty succinctly: 'Deprivation is caused not only by a lack of personal resources but also by insufficient or unsatisfactory community facilities' (Room, 1995: 238). Those living in urban areas are much more likely to be able to draw upon such resources, whereas those in rural areas must show that they are deserving (Sherman, 2006: 893; Milbourne, 2004: 564; Cloke et al., 1995: 353), be able to exploit networks sufficiently (Philip and Shucksmith, 2003: 476), and in some ways be much more savvy with their existing resources, in order to overcome the 'dominant conservative ideologies' (Philip and Shucksmith, 2003: 471) associated with the idyllised nature of rural living in the UK (Milbourne, 2004: 569).

Moreover, resilience for men may look entirely different to resilience for women (MacLeavy, 2011). In rural areas, traditional stereotypes have a particularly strong hold, with employment opportunities to be given first to men (Philip and Shucksmith, 2003). This may affect the working composition of the household, as '[c]oping strategies that may be commonly used in the urban setting and seem financially rational, can be socially and economically irrational in the rural setting' (Sherman, 2006: 892).

One can go on to extend the examples of structural influences on resilience to cultural practices, educational provision, class background and so on. In summary, while a 'resilient' reaction to economic hardship may be an individual response, the conditions that give rise to this cannot be entirely separated from the structural forces that shape them in many ways. 


\section{Path dependence and resilience}

Acknowledging the importance of structure to understanding resilience, as argued in the previous subsection, highlights the fact that 'crises are historical, social and political-economic products' (Ribot, 2014: 671). As such, another relevant framework for examining the social conditions of resilience is 'path dependence'. This approach developed in economics and was gradually adopted by other disciplines including business studies, sociology and politics. Liebowitz and Margolis (1995) explain it as 'a dynamic process [that] exhibits sensitive dependence to initial conditions'. The widespread use of the term to describe a range of circumstances popularised it as a way to emphasise that 'history' or 'initial conditions' matter. Studies in the literature highlight a number of tendencies giving rise to path dependence. One of these is 'reactive sequences' which describe how an initial or contingent condition generates a series of other outcomes, eventually resulting in a particular path of development. The other is called 'self-reinforcing sequences', a process in which an initial condition or a contingent development generates a reinforcement mechanism for the emergence of a particular path with particular outcomes, positive or negative (Mahoney, 2000).

Path dependence was used to explain a wide range of phenomena such as why certain technologies dominate others despite their inefficiency (David 1985); why industries agglomerate in certain regions as in the case of the manufacturing belt in the US (Krugman 1991); why business clusters emerge in areas such as Silicon Valley rather than Route 128 (Kenney and von Burg, 1999); why capitalist development first took place in Europe not in China (Mahoney, 1999); why different regions show disparate economic performance (Martin, 2006); why long-term or structural unemployment exists, and why certain organisational routines may persist (Schreyögg and Sydow, 2011).

However, it is important to note that path dependency is a contested concept, and is certainly not the only option available in policy studies (for a discussion of the advantages and disadvantages of using path-dependency in policy studies, see Kay, 2005). Thelen (2003: 209) argues that the concept 'tends to encourage a rather strict separation of the issues of institutional innovation and institutional reproduction', which is premised on 'a punctuated equilibrium model that emphasises moments of "openness" and rapid innovation followed by long periods of institutional stasis or "lock in"'. Yet, Thelen continues, this is not always the case. Some institutions, for example, show remarkable staying power even in the face of significant shocks. Others may continue to look the same, but undergo extensive change over a long period of time (Thelen, 2003: 210). This being said, path-dependence is not the dominance of one historical trajectory in the absence of alternatives. It should instead be understood as a (sometimes ongoing) restriction of choice rather than an absence of choice (North, 1990: 98; Kay, 2005: 553). Based on this, we argue that, for understanding the development of the concept of resilience to explain how households cope with hardship, pathdependency is useful in explaining the influence of the social background of actors and the development of social support systems.

The relevance of path dependency in explaining resilience has already been discussed in economic geography. For example, Martin and Sunley (2014: 34) view regional economic resilience as a:

...product of history and path dependence: [it] reflects a region's or city's previous pattern and mode of economic growth and development, and together with the latter will influence local attitudes, perceptions and expectations as to the underlying strength (or weakness) of a region's economy and its prospects for recovery from disruptions.

In similar ways, resilience in times of economic hardship at individual or household level is influenced by the general history of social, familial, and cultural development such as the wealth, 
health and knowledge/education of parents, close relatives and previous generations and the choices they made in their lives as well as by the specific histories of regions and social groups. These in turn affect the inherited resources and abilities of current generations and their resilience as well as their need for developing it further.

We use a broader view of path dependence to emphasise the importance of historical trajectory for the analysis of resilience against economic adversities. This means that strict assumptions used by some scholars have been ignored here. For example, a considerable proportion of the studies view path dependence as triggered by a historical 'accident'. For the purposes of this paper, contingent events are not necessary conditions for the explanation of path dependency. This is crucial because while past developments do influence the coping strategies of families in times of hardship, these are not always coincidental. Consider, for example, the role of wealth in resilience. Being rich or poor is hardly ever arbitrary or accidental. The socio-economic status of families has historical trails and is often built upon the wealth and education of previous generations. Even within low-income groups, income differences as well as social stratification may make a considerable difference to the 'degrees of resilience' they would demonstrate. Hence, one may in general find a high level of resilience in some communities or households precisely because they have the resources to develop resilience in the first place. On the other hand, the beginning of a harmful habit such as drug abuse may be considered as a contingent event creating a particular path dependency with negative consequences for the resilience of the person/people and their offsprings. Likewise, a scholarship enabling someone to gain a university degree and enhancing her/his resilience could be viewed as an 'accidental event' but in another system where there is universal access to such opportunities it could just be a historical event.

Furthermore path dependence can be studied in relation to the consequences of 'small initial changes, decisions or random shocks' that change the direction of developments (Page, 2006). While these are important in our context, cumulative developments also matter. Consider, for example, the role of migration as a strategy against economic hardship. Enhanced resilience of current generations may be an outcome of the migration of their parents from areas with limited prospects for education and employment. Quite often first generation migrants engage in a multitude of struggles to make a living in a new country. The cumulative positive changes through generations may eliminate these difficulties for their children and grandchildren.

Finally, the 'lock-in' property is presented as an essential feature of path dependence in that it is considered to create a tendency for its subjects to follow a particular trajectory. This may be a plausible prediction for some cases such as business performance due to firms' purposive functioning, say, for profit maximization. For household resilience in economic hardship however this property of path dependence is likely to have some degree of flexibility. This is due to multidimensional influences and complexities in the determination of individuals' life paths. While particular cumulative or contingent developments may shape the path within which different forms of resilience may be located, these may be modified or radically changed in the process due to factors internal or external to the households. For example, scholars such as Martin and Sunley (2012) explicitly discuss the forces that may lock out the subjects of study of an existing path. The authors do this by taking various considerations into account such as external shocks, or incentives for change offered by 'enabling new paths' in comparison to 'constraining existing paths'. In fact, as Mahoney (2000) argues the theory of path dependence is often conjured to explain deviant developments (e.g., why the industrial revolution took place in England not elsewhere). Deviation from long-term and persistent patterns may open up new paths and hence break the locking-in properties of existing manifestations of path dependence. A longitudinal study by Emmy Werner (1995) and her colleagues in Kauai (Hawaii) provides compelling evidence for lock-outs from path dependence. The study follows 698 individuals born in 1955, from prenatal period to the age of 32, all with high-risk backgrounds involving chronic poverty, family break-ups and parental psychopathology. In the majority of these cases (two-thirds of all participants) the lock-in property 
of path dependence works, i.e., the off-springs remain in chronic poverty and at high risk. However, the remaining one-third, despite being subject to poverty and trauma, develops a capacity to break away from the predicted life path and show sustained competence and recovery from trauma. The study identified various factors that may help individuals to break away from expected trajectories and classified them as those within the individual (such as a positive self-concept, ability to ask for help, special interest and hobbies), the family (such as the ability to recruit surrogate parents, reliable support from carers) and the community (for example the presence of role models, and programmes that give second chances to individuals such as adult education schemes).

Overall, social and familial history shapes the environment within which individuals lead their lives as well as their development. Hence, it has consequences for the resilience of individuals and households despite some possibility for deviance. The exploration of the causes of deviance from path dependence is the subject of another paper. In this paper, we continue with a discussion of the scientific hazards that may result from treating resilience as an individual attribute that could be replicated while overlooking the social conditions within which it emerges.

\section{Problems of neglecting the social conditions of 'resilience'}

\section{The problem of identification}

Definitions of resilience in the context of economic hardship mentioned earlier highlight the abilities, skills and attitudes of individuals to deal with unemployment, low income or lack of income, debt, housing problems, transport etc. The considerations in section 3 raise issues with such individually focused interpretations of resilience. One of these could be termed as the 'identification problem'. This is the possibility that what we identify as resilience in individuals or households may just be a manifestation of structural factors or path dependence reflected in their behaviour. This problem is evident in the questions raised by Burchardt and Huerta (2009): Is resilience an attribute of an individual or a product of interaction with his/her environment? Is it a distinct attribute or does it merely reflect the absence of an unobservable risk factor? More questions can be added. If social and structural influences are also at play, how do we disentangle the individual from the social? Are social scientists well-equipped to analyse unique individual characteristics such as mental strength, positive attitude, etc.?

The implication of all this is that what may appear as lack of resilience in times of economic hardship in one household compared to another may reflect a culmination of social exclusion, highly restrictive institutional support, various social barriers, and so on. Examples can be drawn from new generation migrant households that experience language barriers, a lack of social connections, inadequate knowledge of rights and entitlements in a new setting and limitations of access to welfare provision. All these factors are likely to constrain their chances of substantial recovery in times of economic hardship. A different set of disadvantages exists, for instance, for households with longer term health issues such as severe disability or mental health problems. Their chances of 'beating the odds' against economic adversity through individual action is likely to be circumscribed by disadvantages they confront on a daily basis. How should resilience or a lack of it be judged in households like this? Moreover, there may be cases where a display of resilience in the form of speedy recovery from unemployment and poverty is a manifestation of a middle-class ability to navigate through the system. For example, Mullin and Arce (2008) found that in their study area in Massachusetts, the most resilient families knew how to access support structures outside the family unit, highlighting the role of knowledge and existence of supportive institutions.

In a nutshell, ignoring social conditions of resilience may give rise to an identification problem. For example, when the vulnerability or resilience of households may just be reflecting the differences in 
the ways the social system works for individuals or the history of their development rather than individual traits like mental strength, resourcefulness, adaptability and flexibility. The methodological difficulties of measuring resilience and distinguishing its causes from its consequences imply that making a comparative assessment of individuals in isolation from social structure and history is very difficult indeed. Given this difficulty, there are serious implications for misclassifying individuals. Any conceptualisation of resilience necessarily implies the existence of its opposite (i.e. defining resilience would reveal what is non-resilience). Hence, a misidentification is bound to stigmatise people who by design or default fall into the 'non-resilient' camp. What would be more unfortunate than inflicting such a stigma with the stamp of 'science'?

\section{Intermittence and continuity in resilience or the lack of it}

Another potential problem for conceptualising resilience in isolation from structure, social and personal history would be the difficulty of explaining intermittence and continuities in resilience. The emerging findings from various research studies show that resilience or coping with hardship can be temporary as well as continuous. Background to hardship (e.g., recession) is important. In deindustrialised and deprived areas in the UK, for example, the recent recession is found to be less of a 'shock' and more of a process of compounding long-standing deprivation and vulnerability, especially considering that 40 per cent of unemployment is considered to be long-term (Harrison, 2013: 101). This sort of continuity in dealing with hardship highlights the importance of structural factors rather than showing resilience as a response to a one-off adversity.

More interestingly, other studies found that those who manage to come out of poverty are not immune from returning to poverty. For example, Seccombe (2002: 386) argued that many longitudinal studies indicate that most periods of poverty in the US are less than two years long but a single crisis such as a loss of work or a serious illness can re-expose people to poverty. Another study concluded that of those who managed to escape poverty, half would fall back into it within five years (Stevens, 1994). Philip and Shucksmith (2003: 467) show that the tendency to fall back into poverty is higher in urban than rural areas. Canvin et al. (2009: 241) report similar observations about people living in poverty: "They move on, but they fall back, but it's not a circle, more of an upwards moving spiral". This sort of intermittence cannot be substantiated if resilience is conceptualised in isolation from structural factors as well as path dependency.

The crucial question is then whether resilience should be perceived as a permanent attribute of individuals, i.e., once resilient is always resilient. Intuition as well as the anecdotal evidence from the literature suggests otherwise. It would be difficult to explain such irregularities without reference to social conditions of resilience.

\section{Neglecting the detrimental consequences of 'resilience'}

Resilience when considered as an individual attribute has positive connotations and may evoke admiration although it may also hide the detrimental consequences of being resilient. It is important to recognise the costs at which the positive outcomes associated with resilience are achieved. For example, holding several jobs to make ends meet may be considered as a form of resilience, enabling individuals and families to survive through hardship, remain independent and avoid the stigma associated with being dependent on others. But it may also cause negative health effects (due to the physical and mental strain associated with long working hours), a deterioration in families' work-life balance, a sacrifice from essential leisure time, social activities and ultimately social isolation. The ability to survive on a very low income is also a reflection of resilience and yet again it is unlikely to be free of some undesirable consequences. Support from family and friends in times of hardship can be a sign of resilience but it may also mean transferring risk of hardship onto others. $^{7}$ 
Indeed, a number of scholars such as Harrison (2013) and Batty and Cole (2010) recognise the costs of resilience and the risk of 'burnout'. There is some research supporting the relevance of these concerns. For example, a report by Hossain et al. (2011) found that in the recession, people made changes to their everyday routines. It highlighted that although people were cutting back on socialising, support from family, friends and neighbours mattered greatly. Coping with the rising cost of living has meant less choice, and more time and effort has gone into the everyday work of feeding families on low incomes; for some it has also meant worse diets, colder homes, and less physical mobility (Hossain et al., 2011: 6).

\section{Ideological exploitation of the term 'resilience'}

The term resilience is prone to ideological exploitation when it is considered in isolation from its social conditions. Let us focus on a particular possibility to demonstrate the relevance of this argument. This is the possibility that the resilience discourse 'glosses up the reality' to legitimise the status quo or regressive changes in the wider policy making. For example, the topic of this paper the response of households to the ensuing deep recession following the 2008 crisis- can be viewed from different perspectives. We may provide a positive account of the survival strategies of the households and their agency within a framework of 'resilience' discourse. Alternatively, we may highlight the continuity in poverty (living with more of the same) and its intermittence (getting out of poverty only to fall back into it again), and emphasise insecurity of jobs / income and declining support systems. The difference between these two interpretations may not be a 'thin line' or these may not be the different sides of the same coin. A positive account of the reality may just be a political tool for legitimising structural changes, for example in the welfare system, to the disadvantage of low-income groups who are classified as 'resilient'. It may engender a discourse in which ideologically framed anticipation of 'bouncing back' justifies political negligence with regard to the negative consequences of such policy changes (e.g., higher poverty and destitution).

Indeed, as noted by Harrison (2013: 99), the term resilience '... depoliticizes and shifts responsibility for dealing with the crisis away from those in power. It also creates an expectation that people should 'bounce back'. Similarly, Hickman, et al. (2014: 6) argue that 'an overemphasis on agency has potentially negative policy implications as it provides scope for policy makers to 'blame' low income households for their failure to escape poverty'. Intriguingly, the discourse on resilience has so far sidestepped 'resistance', involving collective responses to injustice, inequality and exploitation, as a form of resilience because they do not conform to accepted notions of advancement that are usually centred on individualistic notions of entrepreneurship and 'aspiration' (e.g., Gregory, 2014; Hoggett, 2001: 38). Developing Hickman et al.'s argument that an overemphasis on agency can result in blaming the poor for their situation, application of this within the current resilience discourse effectively limits the ways in which one can acceptably escape poverty.

In the UK, the current political paradigm for dealing with the consequences of crisis could benefit from a resilience discourse with agent-centric focus. For example, the Conservatives announced a series of public sector cuts (Smith, 2010: 827), implemented them in coalition with the Liberal Democrats (Borges et al., 2013: 397) and argued that the impact of the cuts would be mitigated by an increase in civic-mindedness and voluntarism through the 'Big Society' (MacLeavy, 2011; Cameron: 2007; 2008; 2009). The Coalition Government utilised political and social nostalgia to legitimise these changes in an allusion to the period of enforced austerity of the 1940s, celebrated for the 'blitz spirit' that was cultivated at this time (MacLeavy, 2011: 357; see also Kynaston, 2007; Calder, 1992). Such imagery appeals to the mantra that 'we're all in this together,' legitimising further the welfare reforms and spending cuts, accelerating the trends towards greater individual responsibility (e.g., Jessop, 2003; MacLeavy, 2011: 359; see also Klein, 2007). This legitimisation can also draw attention away from larger systemic issues, including the failings of the global economy and capitalism itself. 
[The] emphasis is placed on the need for the British public to fill the void created by a now retreating state, rather than on the state to develop new policies in response to the emergence of new social risks. Prime Minister David Cameron in his speeches calls for a revival of civil society as a counterweight to the outcomes of laissez-faire economics, which became manifest first in the credit crunch and then in the global recession (MacLeavy, 2011: 359).

MacLeavy's analysis chimes with the findings of other scholars who argue that people are relying more heavily on informal networks of support. Indeed, the role of the third sector increased with the onset of the recession with government-led initiatives such as Third Sector Action Plan (Alcock, 2012), that are justified through ideologically oriented narratives such as the Big Society ${ }^{8}$.

\section{Conclusions}

This paper has contributed to the conceptualisation of the term resilience in the context of its application to individuals and households in hardship. There has been considerable attention paid to this topic particularly since the 2008 crisis. We have argued that the current state of the academic debate is deficient in recognising the role of social conditions within which resilience both arises and may be shaped in different ways and forms.

The paper considers two key dimensions for the contextualisation of the social conditions of resilience. The first is derived from classical social theory and it highlights the importance of social structures. Drawing on the structure-agency debate, we argued that the resilience discourse at present appears to overemphasise the role of agency while neglecting the role of structural influences such class status, operation of markets and the role of the state for the ways individuals and households respond to hardship and crises. The second dimension is based on the theory of path-dependency. We used this framework to explain why history and initial conditions matter for the resilience of social subjects. Accidental and cumulative developments in personal, familial, group or social histories can affect the presence or absence of resilience of current generations although deviation from the existing paths is always a possibility.

Furthermore, it is argued that neglecting, in research, the social conditions of resilience' may lead to a number of problems. Firstly, it may lead to an identification problem in that resilience as an individual trait on the surface may in fact reflect the influence of path dependent or structural factors. Secondly, explaining intermittences in resilience would be difficult if its conceptual development is devoid of the social conditions which give rise to it. Thirdly, a highly positive agentcentric view of this notion may lead to negligence of the costs (personal as well as social) associated with practices/strategies involving resilience. Finally, in isolation from structural and path dependent conditions, the term resilience can be subject to political and ideological exploitation in that regressive changes in society, including social security and support systems, may be justified by narratives highlighting the attitudes of individuals.

\section{Notes}

\footnotetext{
${ }^{1}$ This paper is a product of a research programme entitled Patterns of Resilience during Socioeconomic Crises among Households in Europe. It is funded by the EU Seventh Framework Programme under the Grant Agreement No. 613245.

${ }^{2}$ We are thankful to Ursula Huws for her useful comments on the earlier drafts of his paper.

${ }^{3}$ See for example the UK official documents that aim to define the ways in which local or individual level responses for prevention and recovery could be organised against such acts and developments (Home Office
} 
2012, DCLG 2013) in response to the riots in London following a police shooting but with deeper roots in social and economic inequality and dissatisfaction in 2011.

${ }^{4}$ For simplicity, we use the terms shock, adversity, hardship, disturbance interchangeably

${ }^{5}$ There has been considerable controversy between different Marxian schools on the role of agency, structure and determination. See, for example E.P. Thompson's critique on Louis Althusser (Thompson, 1978).

${ }^{6}$ See, for example Giddens (1999) on risk, responsibility and their implications for the welfare state. This is also supported by O'Boyle 2014.

${ }^{7}$ Point made by Alexandre Calado

${ }^{8}$ The 'Big Society' is a Conservative Party-led drive to increase the autonomy (and, relatedly, the responsibility) of individuals and local communities, giving communities the power to collectively purchase the local pub or post office and to be run as a community concern, for example It relies on community organisation, as well as an increased role for the third sector in social provision.

\section{REFERENCES}

Alcock, P. (2012), 'New Policy Spaces: The Impact of Devolution on Third Sector Policy in the UK', Social Policy and Administration, 46: 2, 219-238

Batty, E. and Cole, I. (2010), 'Resilience and the recession in six deprived communities?', JRF Programme Paper: Poverty and Place Programme

Borges, W., Clarke, H.D., Stewart, M.C., Sanders, D., Whiteley, P. (2013), The emerging political economy of austerity in Britain. Electoral Studies 32(3): 396-403

Bourdieu, P. (1977), Outline of a Theory of Practice, Cambridge University Press

Bourdieu, P. (1984), Distinction: A Social Critique of the Judgement of Taste, London: Routledge

Burchardt, T and Huerta, M. C (2009), 'Introduction: Resilience and social exclusion', Social Policy and Society, 8: 1, 59-61

Calder, A. (1992), The Myth of the Blitz. London: Pimlico. Cameron, D. (2007), 'Making British poverty history', Speech to Chance UK, 16 October 2007.

Cameron, D. (2008), 'We are the champions of progressive ideals', The Independent, 9 May 2008.

Cameron, D. (2009), 'The big society', Hugo Young lecture, London, 10 November 2009.

Canvin, K., Marttila, A., Burstrom, B., and Whitehead, M. (2009), 'Tales of the unexpected? Hidden resilience in poor households in Britain', Social Science and Medicine, 69: 2, 238-245

Chandler, D. (2013), International Statebuilding and the Ideology of Resilience. Politics 33: 4, 276-286

Cloke, P., Goodwin, M., Milbourne, P., Thomas, C. (1995), Deprivation, Poverty and Marginalisation in Rural Lifestyles in England and Wales. Journal of Rural Studies. 11(4): 351-365

CSJ (2011), Strengthening relationships to prevent isolation and loneliness in old age. Centre for Social Justice, Hanover 50 Debate

David, P. A (1985), 'Clio and the Economics of QWERTY' The American Economic Review, 75: 2, 332-7 
Davidson, D.J. (2010), The Applicability of the Concept of Resilience to Social Systems. Society and Natural Resources: An International Journal 23(12): 1135-1149

DCLG (2010), New Forecast Scenarios for UK Mortgage Arrears and Possessions. Department for Communities and Local Government, London: Stationery Office.

De la Rocha, M.G. (2006), 'Vanishing assets: cumulative disadvantage among the urban poor', Annals of the American Academy of Political and Social Science, 606: 1, 68-94

Dewey, J. (1896), 'The reflex arc concept in psychology', Psychological Review, 3: 4, 357-370.

Dolfsma, W and Verbürg, R. (2008), 'Structure, agency and the role of values in the process of institutional change', Journal of Economic Issues, 42: 4, 1031-1054

Duffield, M. (2012), 'Challenging Environments: Danger, Resilience and the Aid Industry', Security Dialogue 43(5), 475-492

Durkheim, E. (1964) The Division of Labor in Society. New York, Free Press [Translation of 1893 edition]

Durkheim, E. (1982) The Rules of Sociological Method, New York, Free Press [Translation of 1895 edition]

Folke, C., Carpenter, S., Elmqvist, T., Gunderson, L., Holling, C.S., Walker, B. (2002), Resilience and Sustainable Development: Building Adaptive Capacity in a World of Transformations. AMBIO: Journal of the Human Environment 31: 5, 437-440

Frost, L. and Hoggett, P. (2008), 'Human agency and social suffering', Critical Social Policy, 28: 4, 438460

Giddens, A (1979) Central problems in Social Theory, Berkeley, CA: University of California Press

Giddens, A (1984) The Constitution of Society, Cambridge: Polity Press

Giddens, A. (1999) 'Risk and responsibility', The Modern Law Review, 62: 1, 1-10

Gregory, L. (2014), 'Resilience or Resistance? Time Banking in the Age of Austerity', Journal of Contemporary European Studies 22: 2, 171-183

Harrison, E. (2013), 'Bouncing back? Recession, resilience and everyday lives', Critical Social Policy, 33: $1,97-113$

Harrow, J. (2009), 'Leadership and Resilience - Local Communities and Service in a Time of Fragmentation. Are There Reasons to be Cheerful?', Paper to the public policy seminar 'Leadership and Resilience: The Strategic Leadership of Local Communities and Local Services in a Time of Fragmentation', University of Edinburgh Business School.

Hickman, P; Batty, E; Dayson, C and Muir, J (2014), “Getting by', coping and resilience in difficult times', Research Paper, Centre for Regional Economic and Social Research, Sheffield Hallam University

Hoggett, P. (2001), 'Agency, Rationality and Social Policy', Journal of Social Policy 30: 1, 37-56

Home Office (2012), PREVENT Strategy. London: Stationery Office 
Hossain, N., Byrne, B., Campbell, A., Harrison, E., McKinley, B., and Shah, P. (2011), 'The impact of the global economic downturn on communities and poverty in the UK', JRF Globalisation, UK poverty and communities programme.

International Monetary Fund (2013), 'Global Resilience, Sustainable Recovery Are IMF Work Priorities', IMF Survey Magazine: Policy, June 6 - accessed online 01/06/15 at http://www.imf.org/external/pubs/ft/survey/so/2013/POL060613A.htm

Jessop, B. (2003), 'From Thatcherism to New Labour' in Overbeek, H. (Ed.), The Political Economy of European Employment, London: Routledge

Kay, A. (2005), 'A Critique of the Use of Path Dependency in Policy Studies', Public Administration 83: 3, 553-571

Keck, M and Sakdapolrak, P. (2013), 'What is social resilience?', ERDKUNDE, 67: 1, 5-19

Kenney, M and von Burg, U. (1999), 'Technology, entrepreneurship and path dependence', Industrial and Corporate Change, 8: 1, 67-103

Klein, N. (2007), The Shock Doctrine: The Rise of Disaster Capitalism. New York: Henry Holt and Co.

Krugman, P. (1991), 'History and industry location' The American Economic Review, 81: 2, 80-83

Kynaston, D. (2007), Austerity Britain: 1945-1951. London: Bloomsbury.

Liebowitz, S. J. and Margolis, S. E. (1995), 'Path dependence, lock-in and history', Journal of Law, Economics and Organization, 11: 1, 205-226

Lister, R. (2002), A Politics of Recognition and Respect: Involving People with Experience of Poverty in Decision making that Affects their Lives. Social Policy and Society 1(1): 37-46

Lowndes, V and McCaughie, K. (2013), 'Weathering the perfect storm? Austerity and Institutional resilience in local government', Policy \& Politics, 41: 4, 533-549

Mackinnon, D., Derickson, K.D. (2013), From resilience to resourcefulness. Progress in Human Geography 37(2): 253-270

MacLeavy, J. (2011), 'A 'new politics' of austerity, workfare and gender?', Cambridge Journal of Regions, Economy and Society, 4: 3, 355-367

Mahoney, J. (2000), 'Path dependence in historical sociology' Theory and Society, 29: 4, 507-548

Martin, R. (2006), 'Path dependence and regional economic evolution', Journal of Economic Geography, 6: 4, pp. 395-437.

Martin, R and Sunley, P. (2012), 'The place of path dependence in an evolutionary perspective on the economic landscape' in Boschma, R. and Martin. R. (Eds), Handbook of Evolutionary Economic Geography, Chichester: Edward Elgar

Martin, R. and Sunley, P (2014), 'On the notion of regional economic resilience', Journal of Economic Geography, advance access

Marx, K. (1907), The Eighteenth Brumaire of Louis Bonaparte, Chicago: Charles H. Kerr \& Co 
Masten, A. (2001), 'Ordinary Magic: resilience processes in development', American Psychologist, 56: $3,227-238$

Mau, S., Mewes, J., and Schoneck, N.M. (2012), 'What determines subjective socio-economic insecurity?', Socio-Economic Review 10: 4, 655-682

Milbourne, P. (2004), 'The local geographies of poverty', Geoforum. 35: 5, 559-575

Milne, A., and Rankine, D. (2013), Reality, Resources, Resilience: Regeneration in a Recession. JRF Programme Paper

Mingione, E. (1987), 'Urban survival strategies, family structure and informal practices', In Smith, M.P., Foggin, J.R. (eds.), The Capitalist City, Oxford: Basil Blackwood.

Mitchell, A. (2013), 'Risk and Resilience: From Good Idea to Good Practice', OECD Development Cooperation Working Papers, No. 13

Mohaupt, S. (2009), 'Review article: resilience and social exclusion', Social Policy and Society, 8: 1, 63-71

Mullin, W.J., and Arce, M. (2008), 'Resilience of families living in poverty', Journal of Family Social Work, 11: 4, 424-440

Myant, M and Drahokoupil, J. (2012), 'International integration, varieties of capitalism and resilience to crisis in Transition Economies', Europe-Asia Studies, 64: 1, 1-33

NEF (2010), Local Resilience is the key to Well-Being. New Economics Foundation, Accessed online http://www.neweconomics.org/blog/entry/local-resilience-is-the-key-to-well-being [last accessed 03/06/2014]

North, D. (1990) Institutions, Institutional Change and Economic Performance, Cambridge, Cambridge University Press

O'Boyle, B. (2013), 'Reproducing social structure', Cambridge Journal of Economics, 37: 5, 1019-1033

OECD (2014), Guidelines for resilience systems analysis, OECD Publishing

Okech, D., Howard, W.J., Mauldin, T., Mimura, Y., Kim, Junghyun. (2012), 'The Effects of Economic Pressure on the Resilience and Strengths of Individuals Living in Extreme Poverty', Journal of Poverty, 16: 4, 429-446

Orthner, D.K., Jones-Sanpei, H., and Williamson, S. (2004), 'The Resilience and Strengths of LowIncome Families', Family Relations 53: 2, 159-167

Page, S. (2006), 'Path dependence', Quarterly Journal of Political Science, 1, 87-117

Parsons, T. (1937), The Structure of Social Action, New York: MacGraw Hill

Philip, L.J., and Shucksmith, M. (2003), 'Conceptualising social exclusion in rural Britain', European Planning Studies, 11: 4, 461-480

Raco, M., and Street, E. (2012), 'Resilience planning, economic change and the politics of postrecession development in London and Hong Kong', Urban Studies, 49: 5, 1065-1087 
Rakodi, C. (1999), A capital assets framework for analysing household livelihood strategies: implications for policy. Development Policy Review 17: 3, 315-342

Ribot, J. (2014), 'Cause and Response: vulnerability and climate in the Anthropocene', The Journal of Peasant Studies 41: 5, 667-705

Rockerfeller Foundation (2015), 100 Resilient Cities. Accessed online 01/06/15 at http://www.100resilientcities.org

Room, G. (1995), 'Conclusions' in Room, G. (Ed), Beyond the Threshold, Bristol: Policy Press

Royce, E. (2009), Poverty and Power: The Problem of Structural Inequality. Marlyand, US: Rowman and Littlefield

Schreyögg, G and Sydow, J (2011), 'Organizational path dependence', Organization Studies, 32: 3, 321-335

Seccombe, K. (2002), 'Beating the odds versus changing the odds', Journal of Marriage and the Family, 62: 4, 384-394

Sherman, J. (2006), 'Coping with rural poverty', Social Forces, 85: 2, 891-913

Smith, M.J. (2010), 'From big government to big society', Parliamentary Affairs, 63: 4, 818-833

Snel, E., and Staring, R. (2001), 'Poverty, migration and coping strategies: an introduction', Focaal European Journal of Anthropology 38: 7-22

SMF (2014), Riders on the Storm: Britain's middle income households since 2007. London: Social Market Foundation

Stevens, A.H. (1994), The Dynamics of Poverty Spells: Updating Bane and Ellwood. The American Economic Review 84: 2, 34-37....

Sewell, W. H. (1992), 'A theory of structure', American Journal of Sociology, 98: 1, 1-29

Thelen, K. (2003), "How Institutions Evolve: Insights from Comparative Historical Analysis" in Mahoney, J. and Rueschemeyer, D. (Eds.), Comparative Historical Analysis in the Social Sciences. Cambridge: Cambridge University Press. Pp. 208-240

Thompson, E. P. (1978), The Poverty of Theory and Other Essays, London: Merlin Press,

Tomlinson, M., Walker, R., and Williams, G. (2008), 'Measuring Poverty in Britain as a Multidimensional Concept, 1991 to 2003', Journal of Social Policy 37: 4, 597-620

Trades Union Congress (TUC) (2012), Economic Report No. 3 (August)

Weber, M. (1978) Economy and Society. Berkeley, CA: University of California Press [Translation of 1922 edition]

Werner, E. E. (1995), 'Resilience in development' Current Directions in Psychological Science, 4: 3, 8185 
World Bank (2013), Building Resilience: Integrating Climate and Disaster Risk into Development. Washington DC: International Bank for Reconstruction and Development/The World Bank 